\title{
Vesicovaginal Fistula: Looking Beyond Incontinence
}

Md. Nurul Amin ${ }^{7}$

Genitourinary fistula is one of the most dreadful complications of obstructed labour encountered by the obstetricians and constitutes a major surgical challenge for the urogynecologist. Victims of fistula become physically cripple, socially outcast and psychologically traumatized. ${ }^{1}$ Professor Edwin $M$ Robertson in his book of "Urologic Injuries in Gynaecology"described this miserable condition as - 'Urinary incontinence in women is one of the most frightful afflictions of human kind. Hour by hour and night by day a leakage wets, excoriates and hurts the victim of this misfortune; clothes are ruined; the bed becomes a nightmare; social intercourse is stopped; a pariah is maid; the family houses an outcast'.2

Fistula usually occurs when a woman is in obstructed labor for days on end without medical help and cannot get a caesarean section. The blood supply to the soft tissues surrounding mother's bladder, rectum and vagina is cut-off due to the prolonged pressure of the baby's head against the mother's pelvis. The injured tissue soon rots away, leaving a hole, or fistula. While the proximate causes of fistulas are physical injuries, the contributing factors are social i.e., poverty, lack of education, childbearing at too early age, lack of medical care social and cultural issues to family planning and most importantly the lack of emergency obstetric care. ${ }^{3}$

Despite its devastating impact on the lives of women, obstetric fistula is still largely neglected in the developing world. Its presence in the community is like the ice-berg phenonmenon of a disease. Only the patients who seek care (tip of the ice-berg) are known to the health care providers and are included in the health statistics. The large portion of the disease remain 'hidden' (submerged portion of the ice-berg), because it affects some of the most marginalized members of the population-poor, young, often illiterate women in remote regions of the world. ${ }^{4}$ In 1989, WHO estimated that more than 2 million girls and women around the world had this condition, with an additional 50,000 to 100,000 new cases occurring each year. These figures were based on women seeking treatment, and were therefore likely to be gross underestimates of the true figures in the community. 5,6

With advanced obstetric care, this notorious fistula is rare in industrialized world but it is still a major health problem in underdeveloped countries, particularly in sub-Saharan Africa and Asia including Bangladesh. The continued incidence of obstetric fistula in low-resource settings is one of the most visible indicators of the enormous gaps in maternal health care between the developed and developing world. Reliable data on obstetric fistula are scarce. ${ }^{7}$ The full extent of the problem has never been mapped. In 2003 UNFPA in collaboration with Engender Health published a survey report titled "Situation Analysis of Obstetric Fistula in Bangladesh" which estimated that the prevalence of fistula is nearly 17 per 10000 ever married women. ${ }^{8}$ This number seems to be a meager figure, but when one considers its social consequence, it will be conspicuously evident that how this small figure causes untold miseries to all who are closely associated with the victims of fistula. And it is because of their untold plight, obstetric fistula is considered as 'near miss death' and its prevalence indicates the health status of a

\footnotetext{
Author information:

${ }^{1}$ Dr. Md. Nurul Amin, Assistant Professor (Community Medicine), Rajshahi Medical College, Rajshahi \& Executive Editor, Ibrahim Cardiac Medical Journal, Ibrahim Cardiac Hospital \& Research Institute, Shahbag, Dhaka.
}

Correspondence: Dr. Md. Nurul Amin, Mobile: 01753178452, e-mail: mdamin01@yahoo.com 
country in general and the level of maternal healthcare in particular. $^{9}$ Besides, the estimated number of fistula cases, as we have already discussed, there are a large number of cases hidden in the community making it a 'public health problem'

In response to the problem, Bangladesh has already taken the global approach of prevention, treatment and rehabilitation. Fistula care is included in the National Maternal Health Strategy. Bangladesh is one of the 20 countries where a campaign to end fistulae is continuing. A National Fistula Centre was established in 2003 to provide a service to patients and training to doctors and nurses. Eight public and seven private fistula centres have been established. Services are free for patients. The training of surgeons and nurses in fistula surgery is structured and conducted by using training manuals and logbooks. In addition to training of local personnel, this centre has also trained international trainees and piloted the International Federation of Gynecology and Obstetrics Fistula Training Manual. ${ }^{10}$ But these centers still much have to do to end fistula. These centers together in association of the Ministry of Health and other concerned ministries and Development Partners should undertake a comprehensive study to find out the actual prevalence of obstetric fistula in Bangladesh and bring the hidden cases under comprehensive fistula care.

Obstetric fistula is a preventable and treatable condition, so no woman should suffer from this misery. Prevention of fistula has two main foci the prevention of early pregnancy and improving access to essential obstetric and basic health care services. ${ }^{11}$ Both issues are directly linked to poverty. Although large-scale poverty reduction activities are clearly outside the scope of this initiative, it is important to recognize that health interventions, whenever possible, should be supported and complemented through poverty reduction activities as well as policy action to address the problem of early child-bearing. ${ }^{8} \mathrm{~A}$ primary health intervention should address the lack of access to timely obstetric care.

Obstetric injury is one minor component of maternal mortality but both are surrogate markers for the quality of antenatal and intrapartum care and reflect the ability and willingness of an administration to provide socialised health care. ${ }^{12,13}$ It is one simple factor among many others defining national status as the developing world. Historically, the recognition that obstetric fistulae were caused by social deprivation was acknowledged and reflected tangibly in the closure of the New York Fistula Hospital less than 100 years after its opening. Such a specialised facility was no longer required, with a dramatic fall in maternal mortality rates reflecting public health improvements resulting from increasing social awareness and prosperity. We are also awaiting for the closure of the specialized fistula centers, when it will no longer be required.

\section{REFERENCES:}

1. Begum SN. Genitourinary Fistula-Experience in a Peripheral Hospital of Bangladesh. J Bangladesh Coll Phys Surg 2011;29(4):207-212. http://dx.doi.org/10.3329/jbcps.v29i4.11328

2. Falk HC. Urologic Injuries in Gynaecology. $2^{\text {nd }}$ edition, FA Davis Company, Philadelphia.1964.

3. Ramphal S \& Moodley J.Vesicovaginal fistula: obstetriccauses. Curr Opin Obstet Gynecol 2006;18(2):147-51.DOI: $10.1097 / 01 . g c 0.0000192980 .92223 .2 d$

4. Lewis G \& de Bernis L. Obstetric Fistula: Guiding principles for clinical management and programme development. Department of Making Pregnancy Safer, World Health Organization Geneva, Switzerland. 2007. Cited: January 13, 2011, Available at: http://www.who.int/making_pregnancy_safer/publications/obstetric_fistula.pdf.

5. Donnay F \& Weil L. Obstetric fistula: the international response. Lancet 2004;3363(9402):71.

6. UNFPA, AMDD,FIGO. Report on the meeting for the prevention and treatment of obstetric fistula 18-19 July, 2001, London. New York: Technical Support Division, UNFPA.

7. Obstetric Fistula needs assessment report, findings from nine African Countries, United Nations Population Fund (UNFPA) and Engender Health. 
8. Waiz NK, Faruqi M, Begum A, Sultana N, Sarker S \& Faisel AJ. Situation Analysis of Obstetric Fistula in Bangladesh. Engender Health, Country Office Bangladesh. September 2003, p. 10. Cited: 11/01/2018, Available at: https://www.popline.org/node/237588

9. UNFPA, AMDD,FIGO. Report on the meeting for the prevention and treatment of obstetric fistula 18-19 July, 2001, London. New York: Technical Support Division, UNFPA

10. Akhter S. International Federation of Gynecology \& Obstetrics. Fistula Training Manual, Vesicovaginal fistulae in Bangladesh, 2012, International News. Cited: 11/01/2018, Available at: https://www.rcog.org.uk/ en/global-network/global-health-news/iternational-ne ws/international-news-september-2012/vesicovaginalfistulae-in-bangladesh/

11. Report on the meeting for the prevention and treatment of Obstetric Fistula, London, June 2001.
12. Wall LL, Karshima JA, Kirschner C \& Arrowsmith SD. The obstetric vesicovaginal fistula: characteristics of 899 patients from Jos, Nigeria. Am J Obstet Gynecol 2004;190:1011-9.

13. United Nations Population Fund, Engender Health. Obstetric Needs Assessment Report: Findings from Nine African Countries. New York: UNFPA, Engender Health; 2003. 